\title{
Comparison of the caudal and lumbar approaches to the epidural space
}

\author{
C M Price, P D Rogers, A S J Prosser, N K Arden
}

\begin{abstract}
Objectives-To investigate the accuracy of placement of epidural injections using the lumbar and caudal approaches. To identify which factors, if any, predicted successful placement.

Methods-200 consecutive patients referred to a pain clinic for an epidural injection of steroid were randomly allocated to one of two groups. Group $L$ had a lumbar approach to the epidural space and group $\mathrm{C}$ a caudal approach to the epidural space. Both groups then had epidurography performed using Omnipaque and an image intensifier to determine the position of the needle.

Results-Body mass index (BMI), grade of operator, and route of injection were predictors of a successful placement. $93 \%$ of lumbar and $64 \%$ of caudal epidural injections were correctly placed $(p<$ 0.001 ). $97 \%$ of lumbar and $85 \%$ of caudal epidural injections clinically thought to be correctly placed were confirmed radiographically. For epidural injections where the clinical impression was "maybe", $91 \%$ of lumbar injections, but only $45 \%$ of caudal injections were correctly placed. Obesity was associated with a reduced chance of successful placement (odds ratio (OR) $0.34(95 \%$ confidence interval $(\mathrm{CI}) 0.17$ to 0.72) BMI >30 $v$ BMI <30). A more senior grade of operator was associated with a reduced chance of successful placement (OR $0.16(95 \%$ CI 0.03 to 0.89$)$ consultant $v$ other). However, small numbers may have accounted for the latter result.

Conclusions-The weight of the patient and intended approach need to be considered when deciding the method used to enter the epidural space. In the non-obese patient, lumbar epidural injections can be accurately placed without $x$ ray screening, but caudal epidural injections, to be placed accurately, require $x$ ray screening no matter what the weight of the patient. (Ann Rheum Dis 2000;59:879-882)
\end{abstract}

Epidural steroids have been used for many years in the management of various rheumatological spinal conditions, including spinal stenosis and sciatica. The mechanisms of action are thought to include an antiinflammatory effect of the corticosteroid, which reduces the inflammatory mediators around the nerve roots and reduces adhesions owing to the volume effect of the injection. ${ }^{1}$ Correct placement of the injection into the epidural space is therefore essential. Both lumbar and caudal (through the sacral hiatus) approaches to the epidural space are regularly used, but little is known of their relative efficacy. One of the main determinants of the relative efficacy of the two approaches will be the accuracy of their placement. The accuracy of placement of the injection has not been extensively studied, but has been reported to be $60-75 \%$ for both approaches, whereas clinical practice would suggest that the figure for the lumbar approach is much higher. ${ }^{2}$ This randomised study aimed at examining the accuracy of placement of lumbar and caudal epidural injections by experienced operators, and identifying other factors that may affect the accuracy of placement of epidural injections.

\section{Methods}

STUDY DESIGN

This was a single centre, randomised trial. Local research and ethics committee approval was granted for the study.

\section{PATIENTS}

Two hundred consecutive patients attending the chronic pain clinic with back related pain requiring an epidural steroid injection were recruited into the study. One patient declined to take part in the study and the next consecutive patient was therefore recruited to make the total number of patients 200 . The patients were randomly allocated to receive an epidural injection using either the caudal or lumbar approach. Other factors that were recorded at baseline were demographic data, including age and sex, body mass index (BMI), operator experience, grade of operator, approach used, diagnosis, and previous back surgery.

\section{INTERVENTIONS}

All epidural injections were performed by experienced anaesthesiologists working within the pain clinic at Queen Alexandra Hospital. All had at least four years' experience in performing epidural injections and were both experienced and confident with the lumbar and the caudal approach to the epidural space. We used a large numbers of investigators to reflect clinical practice and to minimise the risk of cluster effects on the results. The grade and experience of the operator were recorded.

Group L received a lumbar approach to the epidural space. According to operator preference, the patient was placed in either the sitting or lateral position and a midline or paramedian approach was used. A 16 gauge Tuohy needle was advanced using the loss of resistance technique $^{4}$ to either air or saline. 
Table 1 Method of assessment of accuracy of placement of epidural injections

\begin{tabular}{ll}
\hline Method & Scoring system \\
\hline Clinical impression & 1 = Definitely in the epidural space \\
& $2=$ Maybe in \\
3 & $=$ Unable to do \\
& $4=$ Intravenous \\
5 & $=$ Intrathecal \\
& \\
& $1=$ Epidural space \\
& $2=$ Somewhere else \\
& $3=$ Intravenous \\
& $4=$ Intrathecal \\
\hline
\end{tabular}

Table 2 Comparison of baseline characteristics between caudal (C) and lumbar (L) approaches to the epidural space. Results are means (SD)

\begin{tabular}{llc}
\hline Characteristics & Group C & Group $L$ \\
\hline Age & $55.6(16.9)$ & $55.4(6.8)$ \\
Sex $(\mathrm{F}: \mathrm{M})$ & $51: 49$ & $53: 47$ \\
$\mathrm{BMI}\left(\mathrm{kg} / \mathrm{m}^{2}\right)$ & $28.5(4.4)$ & $28.6(5.4)$ \\
Surgery $(\%)$ & $5(5)$ & $3(3)$ \\
Diagnosis: & & \\
$\quad$ Sciatica & 54 & 61 \\
$\quad$ Stenosis & 26 & 25 \\
Other† & 19 & 9 \\
$\quad$ Uncertain & 1 & 5 \\
Grade of operator & & \\
$\quad$ Consultant & 11 & 66 \\
Senior registrar & 74 & 22 \\
$\quad$ Other & 15 & \\
Experience & & \\
$\quad>50$ & 98 & 00 \\
$\quad<50$ & 2 &
\end{tabular}

${ }^{\star} \mathrm{BMI}=$ body mass index.

†ncludes post-laminectomy syndrome, femoral radiculopathy, non-specific low back pain

Group C received the caudal approach. ${ }^{5}$ For this the patient was placed in either the prone or lateral position according to the technique with which the operator was more experienced. An 18 gauge 2" straight bevelled needle was advanced through the sacral hiatus into the epidural space, then the needle checked for minimal resistance to air with a $2 \mathrm{ml}$ syringe and palpation over the sacral region. Full aseptic technique was used.

When the needle was felt to be in the correct space, the operator made a clinical assessment of the accuracy of the placement (table 1), and then performed an epidurogram with $2-5 \mathrm{ml}$ Iohexol contrast medium (Omnipaque) and an image intensifier to assess the radiographic placement of the needle (table 1). Contrast was injected until the operator was confident that they could identify the position of the needle. If the needle was correctly positioned the epidural steroid was injected. If not, the needle was adjusted until correct placement was observed. All operators were fully instructed as to how to assess an epidurogram as described by Collier and White ${ }^{67}$

\section{STATISTICAL ANALYSIS}

Data were analysed with SPSS software, using $t$ tests to compare continuous variables. Fisher's exact test and $\chi^{2}$ tests were used to compare categorical variables. Logistic regression was used to produce odds ratios in both univariate and multivariate models to examine potential predictors of a successful epidural placement. Power calculations showed that to detect a difference of $15 \%$ between groups with
Table 3 Accuracy of placement by clinical impression and fluoroscopy

\begin{tabular}{lcc}
\hline & Caudal & Lumbar \\
\hline Clinical impression & & \\
$\quad$ Definitely & 61 & 74 \\
Maybe & 24 & 23 \\
Couldn't do & 14 & 3 \\
$\quad$ Intravenous & 1 & 0 \\
Fluoroscopy & & \\
$\quad$ Epidural & 64 & 93 \\
Somewhere else` & 18 & 4 \\
Couldn't do & 13 & 3 \\
Intravenous & 5 & 0 \\
\end{tabular}

$\star$ Predominantly subcutaneous.

Table 4 Independent predictors of success for all patients. Results are means (SD)

\begin{tabular}{lll}
\hline & Success & Failure \\
\hline Age & $55.2(16.8)$ & $56.3(17)$ \\
Sex (F:M) & $77: 75$ & $24: 19$ \\
Body mass index & $28(4.4)$ & $30.7(6.1)^{\star}$ \\
Grade & 17 & \\
$\quad$ Consultant & 105 & $6^{\star}$ \\
$\quad$ Senior registrar & 35 & 25 \\
$\quad$ Other & & 2 \\
Diagnosis: & 94 & 21 \\
$\quad$ Sciatica & 39 & 12 \\
Stenosis & 18 & 10 \\
$\quad$ Other† & 7 & 1 \\
Previous surgery & & \\
Route of injection: & 93 & $77^{\star \star}$ \\
$\quad$ Lumbar & 64 & 36 \\
Caudal & & \\
\hline
\end{tabular}

${ }^{\star} \mathrm{p}<0.05 ;{ }^{\star \star} \mathrm{p}<0.001$

†Six classified as uncertain.

$90 \%$ power at the 0.05 significance level would require 200 patients in total. $^{23}$

\section{Results}

Of the 200 patients recruited, only one did not wish to participate in the study. Baseline characteristics between the two groups were not significantly different (table 2). Sciatica was the most common indication for epidural steroid injection $(115 / 200(58 \%))$. In six patients the exact diagnosis did not clearly fit into a single diagnostic category and they were labelled as uncertain diagnosis. Fourteen operators took part in the study: five consultants, two senior registrars, three staff grade doctors, and four third year trainees. There was no significant difference in the proportion of injections done by each grade between the two approaches (table 2).

Table 3 shows the results of the clinical and radiographic impression of placement. $93 \%$ of lumbar but only $64 \%$ of caudal epidural injections were correctly placed within the epidural space when assessed by fluoroscopy. Of epidural injections thought to be definitely in the epidural space on clinical grounds, $97 \%$ of lumbar and $85 \%$ of caudal epidural injections were confirmed on fluoroscopy. For epidural injections where the clinical impression was "maybe" $91 \%$ of lumbar injections, but only $45 \%$ of caudal injections, were correctly placed on fluoroscopy. Of note is that four intravenous injections went undetected by clinical impression. Most incorrectly placed caudal injections were subcutaneous. The actual position of these incorrectly placed caudal injections was confirmed by multi-angle screening. 
Table 5 Factors that may affect success of placement using multivariate analysis

\begin{tabular}{ll}
\hline Factor & $\begin{array}{l}\text { Odds ratio of success: } \\
\text { failure }(95 \% \mathrm{CI})\end{array}$ \\
\hline $\begin{array}{l}\text { Route lumbar } v \text { caudal } \\
\text { Grade of operator: }\end{array}$ & $8.12(3.17$ to 20.8$)$ \\
$\quad$ Consultant $v$ other & $0.09(0.01$ to 0.72$)$ \\
$\quad$ Senior registrar $v$ other & $0.10(0.01$ to 0.81$)$ \\
Body mass index $>30 v<30$ & $0.28(0.12$ to 0.65$)$ \\
\hline
\end{tabular}

BMI, grade of operator, and route of injection were the only predictors of a successful placement (tables 4 and 5). In univariate analysis, route of injection was the strongest predictor of successful placement, with the lumbar route more likely to be successful with an odds ratio of 7.5 (95\% CI 3.1 to 17.8 ) compared with the caudal route. Obesity, BMI $>30$, was associated with a reduced chance of successful placement, OR 0.34 (95\% CI 0.17 to 0.72 ). A more senior grade of operator was associated with a reduced chance of successful placement: consultant $v$ specialist registrar/ other grade, OR 0.16 (95\% CI 0.03 to 0.89 ). These variables were all statistically significant predictors of successful placement in a multivariate model which included all three variables (table 5).

\section{Discussion}

This study has found that even when using experienced operators, caudal epidural injections are far less accurately placed than lumbar epidural injections (64\% v 93\%). Furthermore, a significant number of caudal epidural injections are misplaced even when felt probably to be correctly placed, leading to a false sense of confidence. Of most concern is that accidental intravenous injections may go undetected. This is important when using local anaesthetic, as convulsions and arrhythmias may occur when using even a small dose of local anaesthetic. The caudal approach is more likely than the lumbar approach to produce an intravenous placement of injection $(6-9 \%))^{23}$

Factors that may predict success may be divided into patient, operator, and technical factors. Of the patient factors, obesity was the only influence on accuracy of placement that was statistically significant for both methods (OR $0.23 v 0.47$ for success caudal $v$ lumbar with $\mathrm{BMI}>30$ ). BMI was higher in this study than for the general population, reflecting the higher levels of inactivity seen in patients with various back and leg conditions. Grade of operator appeared to predict chance of success, though cumulative experience did not. It may be that once sufficient clinical experience is obtained to master the technique, continuing experience becomes more important However, the number of epidural injections performed by consultants was very small. The results would be easily influenced by a small number of difficult cases.

Our methodology may be criticised on several aspects. A standardised approach to the epidural space was not used by the group. This was because, in a pragmatic study such as this, we felt it was best to use the technique the individual was most familiar with in their usual clinical practice. All approaches were, however, standard approaches. ${ }^{45}$ We did not use the "whoosh" test, as previously described, to improve accuracy because of the risk of venous air embolism. ${ }^{89}$ The equipment used represents that favoured overall by the group and was similar to that used in the rest of the UK. This was then standardised for both approaches. Owing to staffing levels, an independent assessment of the $x$ ray result was not possible. However, all participant operators were taught how to recognise an epidurogram. If there was any doubt then a plate was made, to be examined later by the group. We are not aware of there being a recognised scoring system for epidurograms. This would have been helpful in improving reliability.

There have been several previous studies in this area. However, no study has examined potential patient factors that may influence placement. The most important study was a prospective study of 334 patients. ${ }^{3}$ This found that $25 \%$ of caudal epidural injections and $30 \%$ of lumbar epidural injections were incorrectly placed. Pain was used as the main determinant of incorrect placement; however, an injection of air may be painless even though it is in the wrong place. The incidence of intravascular caudal injections was $6.4 \%$. It is not clear whether continuous loss of resistance to air was used during the lumbar approach or merely when the space had been identified. The latter method would have resulted in many incorrect placements. Obesity was identified as a possible factor, though this was not quantified. Renfrew et al found that the success rate was $61 \%$ with caudal injections, ${ }^{2}$ and this was related to experience, though other potential factors were not examined. We found a similar incidence with experienced operators. El Khoury et al found the incidence of incorrect placement was reduced with fluoroscopy and contrast to $2.5 \%$ and recommended that fluoroscopy always be performed with the caudal approach. ${ }^{10}$ We would endorse this. For lumbar epidural injections, Fredman et al found a correct placement rate of $89 \% .{ }^{11}$ This, however, was for patients with failed back surgery when the epidural space might have been highly abnormal. Thus our finding of $93 \%$ success is probably representative of other centres.

We therefore feel that fluoroscopy and contrast injection should routinely be used for caudal, but not for lumbar, epidural injections. This is to determine the position and lack of intravenous placement. Obese patients (BMI >30) should ideally always be screened with both approaches. Results from studies looking at efficacy with caudal injections should be interpreted with caution if no fluoroscopy was used. When future studies are planned using caudal epidural injections or obese patients fluoroscopy should always be performed. This has significant design and cost implications.

\section{Conclusions}

We conclude therefore that the weight of the patient and intended approach need to be considered when deciding the method used to enter the epidural space. We would suggest that 
in the non-obese patient lumbar epidural injections can be accurately placed without $x$ ray screening. Caudal epidural injections, however, do require $x$ ray screening to be accurately placed no matter the weight of the patient.

1 Reydivik B, Brown M, Lundborg G. Pathoanatomy and pathophysiology of nerve root compression. Spine 1984;9:7-15.

2 Renfrew DL, Moore TE, Kathol MH, El-Khoury GY, Lemke JH, Walker CW. Correct placement of epidural steroid injections: fluoroscopic guidance and contrast administration. Am J Neuroradiol 1991;12:1003-7.

3 White AH, Derby R, Wynne G. Epidural injections for the White AH, Derby R, Wynne G. Epidural injections for the
diagnosis and treatment of low back pain. Spine 1980;5: diagnosis

4 Armitage EN. Lumbar and thoracic epidural anaesthesia. In: Wildsmith JAW, Armitage EN, eds. Principles and practice of regional anaesthesia. Edinburgh: Churchill Livingstone, 1990:81-102.
5 Martin LVH. Sacral epidural block. In: Wildsmith JAW, Armitage EN, eds. Principles and practice of regional anaesthesia. Edinburgh: Churchill Livingstone, 1990:10310

6 Collier CB. Why obstetric epidurograms fail: a study of epidurograms. International Journal of Obstetric Anesthesia 1996;5:19-31.

7 White $\mathrm{AH}$. Injection techniques for the diagnosis and treatment of low back pain. Orthop Clin North Am 1983;14: 553-67.

8 Eastwood D, Williams C, Buchan I. Caudal epidurals: the whoosh test. Anaesthesia 1998;53:296-307.

9 Dearlove O, Walker RWM, Bigeon JY. The whoosh test and caudal anaesthesia [letter]. Anaesthesia 1998;53:829.

10 El Khoury, Ehara S, Weinstein JN, Montgomery WJ, Kathol $\mathrm{MH}$. Epidural steroid injection: a procedure ideally performed with fluoroscopic control. Radiology 1988;168: 2:554-7.

11 Fredman B, Nun MB, Zohar E, Iraqi G, Shapiro M, Gepstein R, et al. Epidural steroids for treating "failed back surgery syndrome": is fluoroscopy really necessary? Anaesthesia and Analgesia 1999;88:367-72. 